

\section{Kalpataru}

Jurnal Sejarah dan Pembelajaran Sejarah

Volume 7, Nomor 1, Juli 2021

\section{Chief Editor}

Drs. Sukardi, M.Pd.

\section{Editor}

Dr. Muhamad Idris, M.Pd.

Eva Dina Chairunisa, M.Pd.

Jeki Sepriady, S.Pd.

\section{Reviewer}

Dr. Tahrun, M.Pd.

Drs. Supriyanto, M.Hum.

Dra. Retno Purwati, M.Hum.

Dr. Nor Huda Ali, M.Ag., M.A.

Dr. Budi Agung Sudarman, S.S., M.Pd.

Dr. Purmansyah, M.A.
(Universitas PGRI Palembang)

(Universitas Sriwijaya Palembang)

(Balai Arkeologi Sumatera Selatan)

(Masyarakat Sejarawan Indonesia Sumsel)

(Balai Bahasa Provinsi Sumatera Selatan)

(Universitas Muhammadiyah Palembang)

\footnotetext{
Alamat Redaksi

Program Studi Pendidikan Sejarah

Fakultas Keguruan dan IImu Pendidikan Universitas PGRI Palembang

Telp. 0711-510043

Email: jurnalkalpatarusejarah@gmail.com

Website: https://jurnal.univpgri-palembang.ac.id/index.php/Kalpa
} 


\section{Kalpataru}

JURNAL SEJARAH DAN

PEMBELAJARAN SEJARAH

Terbit dua kali setahun pada Juli dan Desember

Diterbitkan oleh:

Program Studi Pendidikan Sejarah Jurusan Pendidikan IPS

Fakultas Keguruan

dan IImu Pendidikan

Universitas PGRI Palembang

\section{DAFTAR ISI}

Nilai Budaya Masjid Jami' Sungai Lumpur Kelurahan II Ulu Palembang Sebagai Sumber Pembelajaran Sejarah

Maya Susanti, Muhamad Idris, Aan Suriadi.... $1-9$

Analisis Konsep Gender Dalam Undang-Undang Simbur Cahaya Sebagai Sumber Pembelajaran Sejarah Ruli Annisa, Muhamad Idris, Kabib Sholeh .... $10-18$

Perbedaan Model Pembelajaran Student Teams Achievement Divisions (STAD) dengan Model Pembelajaran Jigsaw Terhadap Hasil Belajar Siswa Pada Mata Pelajaran Sejarah di SMA Negeri 2 Mesuji Taufik Sidiki Al-Haq, Nur Ahyani, Ida Suryani.

Pengaruh Pemanfaatan Media Youtube Terhadap Hasil Belajar Siswa Mata Pelajaran Sejarah di SMK PGRI 2 Palembang

Riska Anggraini, Nur Ahyani, Ida Suryani. 28-36

Pengaruh Metode Pembelajaran Daring Terhadap Hasil Belajar Siswa Pada Mata Pelajaran Sejarah di Kelas XI IPA SMA Shailendra Palembang

Christina Leovita Saragih, Nur Ahyani, Aan Suriadi. $37-42$

Pengembangan Media Pembelajaran Digital Bukti-bukti Bangunan Masjid Kuno di Palembang Berbasis Android Varokah Widiyanti, Eva Dina Chairunisa, Ahmad Zamhari .

\section{Gambar Cover:}

Pohon Kalpataru

Candi Prambanan

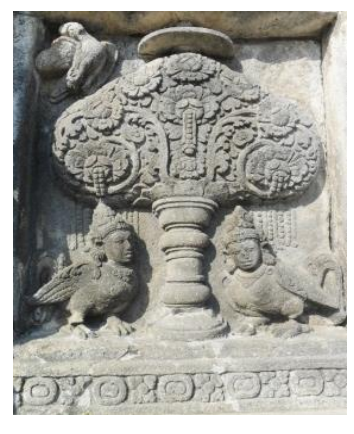

Koleksi: Muhamad Idris
Hubungan Jawa-Melayu Dalam Dunia Arsitektur Melayu Sumatera Selatan Reyvaldi Uyun, Muhamad Idris, Ahmad Zamhari.

Kondisi Politik Orde Baru di Gorontalo Tahun 19681998

Ferrari Yuliawati S, Suryo Ediyono. $61-67$

Nilai-nilai Sejarah dan Budaya Ikonografi Megalith di Lahat Sebagai Sumber Pembelajaran Sejarah Nasional Jainal Arifin, Sukardi, Dina Sri Nindiati.

Minat Siswa Terhadap Sejarah dan Budaya Palembang di SMA Negeri 15 Palembang Febbi Astuti, Muhamad Idris, Kabib Sholeh. $.77-82$ 
Kalpataru, Volume 7, Nomor 1, Juli 2021 (28-36)

\title{
PENGARUH PEMANFAATAN MEDIA YOUTUBE TERHADAP HASIL BELAJAR SISWA MATA PELAJARAN SEJARAH DI SMK PGRI 2 PALEMBANG
}

\author{
Riska Anggraini \\ Mahasiswa Program Studi Pendidikan Sejarah, FKIP Universitas PGRI Palembang \\ Email: rizkaaarni@gmail.com \\ Nur Ahyani \\ Dosen Program Studi Pendidikan Sejarah FKIP Universitas PGRI Palembang \\ Email: nurahyani63@gmail.com \\ Ida Suryani \\ Dosen Program Studi Pendidikan Sejarah FKIP Universitas PGRI Palembang \\ Email: ida954321@gmail.com
}

\begin{abstract}
ABSTRAK
Permasalahan penelitian ini adalah siswa kurang tertarik dalam pembelajaran sejarah karena pembelajaran hanya berpusat pada guru dan membuat siswa kurang aktif dalam kegiatan pembelajaran, serta kurangnya penggunaan media dalam kegiatan pembelajaran oleh guru. Adapaun tujuan penelitian ini adalah untuk mengetahui pengaruh pemanfaatan media Youtube pada proses pembelajaran terhadap hasil belajar siswa. Sampel penelitian ini adalah siswa kelas X TKRO 2 sebagai kelas eksperimen berjumlah 36 siswa dan kelas $X$ TKRO 1 sebagai kelas kontrol berjumlah 36 siswa. Metode yang digunakan adalah metode eksperimen, untuk mengetahui apakah ada pengaruh variabel bebas terhadap variabel terikat. Teknik pengambilan data penelitian ini adalah observasi, tes, dan dokumentasi. Kemudian teknik analisis data adalah uji normalitas data, uji homogenitas data, dan uji hipotesis yang menggunakan Uji-t. Berdasarkan hasil penelitian yang telah dilakukan di SMK PGRI 2 Palembang dan hasil analisis data, maka didapat hasil perhitungan pada Uji-t yaitu thitung adalah 7,54, dan tabel dengan $d k=n 1+n 2-2$ dan taraf signifikan 5\% maka tabel adalah 1,67. Sehingga thitung $>$ tabel maka Ho ditolak dan Ha diterima Sehingga dapat disimpulkan bahwa ada pengaruh positif yang signifikan dari media pembelajaran Youtube di mana kelas eksperimen lebih baik dari pada kelas kontrol.
\end{abstract}

Kata Kunci: Media Youtube, Hasil Belajar Siswa.

\section{A. PENDAHULUAN}

Pendidikan merupakan suatu hal yang sangat penting dan mendasar pada saat sekarang ini, di mana sejak kecil semua orang sudah pasti akan diberikan pendidikan oleh orang tua. Pendidikan juga sangat berperan penting pada kemajuan disuatu bangsa karena untuk menciptakan generasi yang berkualitas untuk bangsa di masa sekarang maupun masa yang akan datang. Menurut Oemar Malik menjelaskan bahwa "Pendidikan merupakan memberikan kita pembekalan yang tidak ada pada masa kanak-kanak, akan tetapi membutuhkannya pada masa dewasa".

Pendidikan menurut Ki Hajar Dewantara adalah "Menuntun segala kekuatan kodrat yang ada pada anak-anak agar mereka sebagai manusia dan sebagai anggota masyarakat bisa mencapai keselamatan dan kebahagiaan yang setinggi-tingginya". Definisi pendidikan menurut Tilaar adalah "proses hominisasi dan humanisasi, proses yang harus ditumbuhkan sejak seseorang di bangku pendidikan dasar, seseorang yang sedang berjalan di dalam lingkungan kehidupan keluarga dan masyarakat yang berbudaya, saat ini dan di masa yang akan datang". Jadi menurut penulis dari pengertian di atas pendidikan adalah suatu cara untuk menambah ilmu agar dapat mencapai cita-cita yang diinginkan.

Pembelajaran dapat diartikan sebagai kerjasama antara guru dan siswa dalam 
memanfaatkan segala potensi dan sumber yang ada, baik potensi yang bersumber dari dalam diri siswa itu sendiri seperti minat, kemampuan, gaya belajar, dan hal lain yang berkaitan dengan proses pembelajaran. Tujuan pembelajaran pada hakikatnya adalah perubahan perilaku siswa, baik perubahan perilaku dalam bidang kognitif, afektif, maupun psikomotor (Agung, 2013:3-5).

Menurut Syaiful "Pembelajaran ialah membelajarkan peserta didik menggunakan asas pendidikan. Kemudian menurut Abdul Ghofir pembelajaran adalah usaha guru atau pendidik membimbing, mengarahkan, mengorganisir belajar" (Hanafi dkk, 2018:5859). Dari pendapat di atas dapat ditarik kesimpulan bahwa pembelajaran merupakan suatu aktifitas yang dilakukan oleh guru dan siswa dalam belajar agar mencapai suatu tujuan yang diinginkan.

Pengajaran sejarah di sekolah bertujuan agar siswa memperoleh kemampuan berpikir dan memahami sejarah dari perspektif sejarah. Pembelajaran sejarah bertujuan agar siswa memahami proses perubahan dimensi dan perkembangan manusia saat ini, membentuk perspektif dan pencerahan sejarah, serta menemukan, memahami, dan mengungkap identitas nasional masa lalu, sekarang, dan masa depan di dunia yang terus berubah.

Menurut Ifadah (2020) "Di era digital sekarang ini tidak jarang ditemui komunitas yang diawali dari adanya komunikasi melalui dunia maya". Kemudian kita melihat fenomena generasi muda saat ini, khususnya siswa yang kurang tertarik dengan pembelajaran sejarah. Merasa kurang peduli dan bosan belajar sejarah. Hanya siswa tertentu yang dapat belajar secara aktif. Maka dengan perkembangan pembelajaran saat ini juga terjadi perubahan yaitu guru hanya menjadi promotor pengajaran, bukan pusat pembelajaran. Kemudian ada penemuanpenemuan baru dalam pendidikan yang dapat mendorong siswa untuk belajar lebih giat, khususnya belajar sejarah. Untuk mencapai proses pembelajaran yang efektif, siswa dapat menerima informasi atau pembelajaran dari internet dan dapat mengakses berbagai pembelajaran dengan lebih mudah. Di sinilah contoh pendidikan menjadi sangat berubah, karena internet bisa digunakan kapan saja, di mana saja. Ternyata di generasi sekarang ini, sangat mudah menggunakan media sosial daripada hanya membaca atau belajar. Yang bisa digunakan guru untuk membuat siswa tertarik belajar sejarah adalah dengan menggunakan media Youtube. Dengan adanya media sosial Youtube dapat membuat siswa sangat lebih mudah mencari informasi terkait pelajarannya. Apalagi pada Kurikulum 2013 siswa sudah diajak untuk belajar memanfaatkan kemajuan teknologi dengan baik dan bijak. Dari permasalahan tersebut peneliti tertarik terhadap masalah hasil belajar siswa dalam pembelajaran sejarah. Karena pendidikan dan pembelajaran sangat penting dalam membentuk karakter bangsa.

Aktivitas belajar sangat penting dalam meningkatkan hasil belajar siswa. Siswa tak jarang merasa bosan ditambah cara guru mengajar dan menjelaskan materi hanya mononton menggunakan metode itu-itu saja seperti ceramah, kemudian kadang kala siswa disuruh menghafal materi yang menciptakan minsed pembelajaran sejarah yang membosankan siswa. Menurut Hakim (2008:3) "Belajar akan lebih bermakna apabila menggunakan media pembelajaran yang dapat membuat siswa lebih aktif berfikir daripada belajar hanya dengan hafalan". Sebaliknya belajar menggunakan hafalan mungkin hasilnya hanya tampak pada bentuk kemampuan mengingat pelajaran itu saja. Maka diperlukan suatu upaya untuk meningkatkan hasil belajar siswa menggunakan pemanfaatan media sosial yaitu Youtube.

Youtube merupakan jaringan media sosial yang paling banyak diminati masyarakat dewasa ini. Dalam konteks pembelajaran, Youtube dapat dimanfaatkan sebagai salah satu media ajar. Hal ini disinyalir dapat meningkatkan minat dan motivasi belajar siswa. Youtube bisa menjadi alternatif dalam pembelajaran sejarah dan mengembangkan minat belajar siswa yang terkadang sering merasa bosan dengan media pembelajaran yang diajarkan.

Berdasarkan latar belakang tersebut maka dilakukan penelitian tentang "Pengaruh Pemanfaatan Media Youtube Terhadap Hasil 
Belajar Siswa pada Mata Pelajaran Sejarah tepatnya di SMK PGRI 2 Palembang". Tujuan dari penelitian ini adalah untuk mengetahui ada tidaknya pengaruh pemanfaatan media Youtube terhadap hasil belajar siswa di SMK PGRI 2 Palembang.

\section{B. METODE PENELITIAN}

Berdasarkan tujuan penelitian ini adalah untuk mengetahui apakah ada pengaruh media Youtube terhadap hasil belajar siswa mata pelajaran sejarah di SMK PGRI 2 Palembang, maka metode penelitian ini adalah eksperimen dengan pendekatan kuantitatif eksperimen. Penelitian eksperimental adalah penelitian yang secara ketat mengikuti penelitian ilmiah. Desainnya mencakup hipotesis, variabel yang dapat dimanipulasi oleh peneliti, dan variabel yang dapat diukur, dihitung, dan dibandingkan. Penelitian eksperimen bertujuan untuk mengetahui hubungan antara dua variabel, yaitu variabel terikat dan variabel bebas (Duli, 2019:9).

Penelitian ini dilaksanakan di SMK PGRI 2 Palembang yang berlokasi di Jalan Sapta Marga No. 30 Bukit Sangkal, Kecamatan Kalidoni, Palembang, Sumatera Selatan. Yang menjadi populasi dalam penelitian ini adalah seluruh siswa kelas X SMK PGRI 2 Palembang yang berjumlah 435 siswa dan terdiri dari 14 kelas. Namun yang menjadi sampel penelitian ini ada 2 kelas yakni kelas X TKRO 2 sebagai kelas eksperimen yang berjumlah 36 siswa dan kelas $X$ TKRO 1 sebagai kelas kontrol yang berjumlah 36 siswa.

Teknik pengumpulan data yaitu observasi melalui data yang diambil adalah tentang bagaimana aktifitas siswa di sekolah, dan proses pembelajaran sejarah dilakukan, kemudian tes hasil belajar digunakan untuk mengukur peningkatan hasil belajar mata pelajaran sejarah yang diperolah siswa setelah menerapkan media Youtube sebagai media pembelajaran (Rifai: 2020). Pada penelitian ini tes yang digunakan adalah berbentuk soal pilihan ganda sebanyak 20 soal dibagikan kepada peserta didik yang menjadi subjek penelitian. Kemudian dokumentasi dalam penelitian ini mengumpulkan data yang dikumpulkan guru sejarah dalam bentuk arsip, perangkat guru dan absensi siswa.

Teknik analisis data pada penelitian ini yaitu Uji-t. Untuk melakukan Uji-t diperlukan uji normalitas, dan uji homogenitas data, untuk mengetahui apakah ada pengaruh terhadap dari pembelajaran yang menggunakan media Youtube maupun tidak menggunakan media Youtube.

\section{HASIL DAN PEMBAHASAN Uji Normalitas Data}

Uji normalitas data merupakan syarat yang harus dilakukan sebelum menganalisis suatu data. Uji normalitas data dilakukan untuk mengetahui apakah data yang diolah normal atau tidak normal. Karena uji statistik dapat digunakan apabila data tersebut terdistribusi normal. Uji normalitas pada penelitian ini berdasarkan dari daftar distribusi frekuensi makan dapat ditentukan rata-rata $(X)$, simpangan baku ( $\mathrm{S}^{2}$ ), dan modus (Mo). Hal ini berkaitan dengan Uji-t yang hanya dapat digunakan bila data yang di peroleh terdistribusi normal.

\section{Uji Normalitas Data Kelas Eksperimen}

Setelah melakukan penelitian pada siswa kelas X TKRO 2 yang menjadi kelas eksperimen dan telah dilakukan tes hasil belajar siswa maka didapat nilai hasil belajar siswa. Berikut adalah nilai hasil belajar siswa kelas eksperimen agar dapat dianalisis datanya:

$\begin{array}{llllll}80 & 55 & 95 & 80 & 70 & 85 \\ 75 & 80 & 50 & 80 & 90 & 85 \\ 95 & 65 & 80 & 55 & 90 & 80 \\ 95 & 75 & 80 & 85 & 90 & 75 \\ 95 & 90 & 80 & 70 & 80 & 75 \\ 85 & 90 & 75 & 85 & 95 & 90\end{array}$

Data nilai tes hasil belajar siswa kelas $X$ TKRO 2 pada kelas eksperimen menunjukkan bahwa ada 6 siswa yang tidak memenuhi KKM, sedangkan 30 siswa lainnya mendapatkan nilai yang baik yaitu memenuhi KKM. Nilai terendah yang didapatkan siswa adalah 50 sedangkan nilai tertinggi yang didapatkan siswa yaitu 95 . Kemudian disusun dalam daftar distribusi frekuensi dengan langkah-langkah menentukan 
rentang, banyak kelas, dan panjang kelas sebagai berikut:

1. Rentang $=$ Nilai Tertinggi - Nilai Terendah

$R=X_{\max }-X_{\min }$ (Sumardi, 2020:160)

$$
=95-50
$$$$
=45
$$

Jadi, Rentang nilai adalah 45.

2. Banyak Kelas

$=1+(3,3) \log n$

$=1+(3,3) \log 36$

$=1+5,13$

$=6,13$

$=6$

Jadi, banyak kelas yang diambil adalah 6 kelas.

3. Panjang Kelas Interval

$=\frac{\text { Rentang }}{\text { Banyak Kelas Interval }}$

$=\frac{45}{6}$

$=7,5$

$=8$

Jadi, panjang kelas interval yang diambil adalah 8.

Kemudian, nilai siswa didistribusikan dalam daftar distribusi frekuensi kelas ekseprimen dengan data yang sudah dihitung. Tabel daftar distribusi kelas eksperimen adalah sebagai berikut:

Tabel 1

\section{Daftar Distribusi Frekuensi Kelas Eksperimen}

\begin{tabular}{|c|c|c|c|c|c|c|}
\hline No. & $\begin{array}{l}\text { Kelas } \\
\text { Interval }\end{array}$ & $\mathrm{Fi}$ & $X i$ & Fi.Xi & $X i^{2}$ & Fi.Xi' ${ }^{2}$ \\
\hline 1. & $50-57$ & 1 & 53,5 & 53,5 & 2862,25 & 2862,25 \\
\hline 2. & $58-65$ & 2 & 61,5 & 123 & 3782,25 & 7564,5 \\
\hline 3. & $66-73$ & 3 & 69,5 & 208,5 & 4830,25 & 14490,75 \\
\hline 4. & $74-81$ & 13 & 77,5 & 1007,5 & 6006,25 & 78081,25 \\
\hline 5. & $82-89$ & 6 & 85,5 & 513 & 7310,25 & 4386,15 \\
\hline 6. & $90-97$ & 11 & 93,5 & 1028,5 & 8742,25 & 96164,75 \\
\hline & Jumlah & $\begin{array}{c}\mathrm{Fi} \\
= \\
36\end{array}$ & $\begin{array}{l}X i= \\
441\end{array}$ & $\begin{array}{c}\sum F i . X i \\
=2902\end{array}$ & $\begin{array}{l}\sum X i^{2}= \\
33533,5\end{array}$ & $\begin{array}{c}\sum F i . X i^{2} \\
=238833\end{array}$ \\
\hline
\end{tabular}

Terlihat pada tabel daftar distribusi kelas eksperimen yaitu kelas X TKRO 2 menunjukkan yang paling banyak mendapatkan nilai yaitu pada nilai 74-81 dengan jumlah 13 orang, dan yang paling sedikit yaitu mendapatkan nilai 50 57 hanya satu orang. Data dalam diagram dapat dilihat pada gambar di bawah:

\section{Gambar 1}

Diagram Distribusi Frekuensi Hasil Belajar Kelas Eksperimen

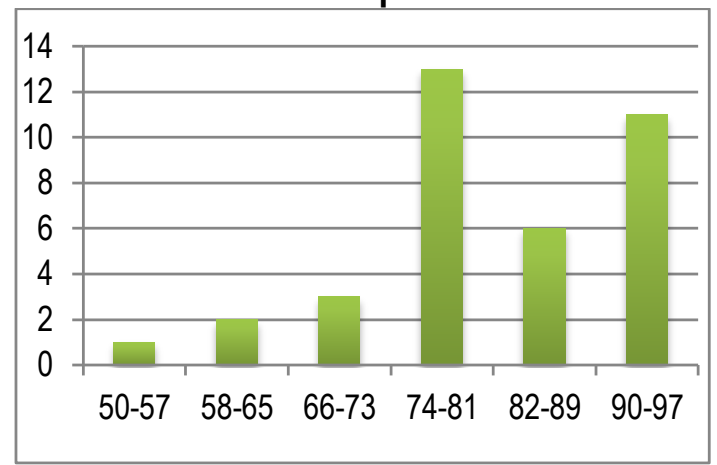

Selanjutnya mencari nilai rata-rata, modus, dan simpangan baku dari hasil belajar kelas eksperimen. Yang akan dilihat pada data di bawah ini:

4. Nilai Rata-rata

$$
\begin{aligned}
\bar{x} & =\frac{\sum \mathrm{Fi} . \mathrm{Xi}}{\sum \mathrm{Fi}} \\
\bar{x} & =\frac{2902}{36} \\
\bar{x} & =80,61 \\
& =81
\end{aligned}
$$

Jadi, nilai rata-rata hasil belajar kelas eksperimen adalah 81.

5. Modus

$$
\begin{aligned}
& b=74-0,5=73,5 \\
& b_{1}=13-3=10 \\
& b_{2}=13-6=7 \\
& p=8 \\
& M_{0}=b+p\left(\frac{b_{1}}{b_{1}+b_{2}}\right) \\
& M_{0}=73,5+8\left(\frac{10}{10+7}\right) \\
& M_{0}=73,5+4,70 \\
& M_{0}=78,2
\end{aligned}
$$

Jadi, Modus atau nilai yang paling sering muncul adalah nilai 78,2 . 
6. Simpangan Baku

$$
\begin{aligned}
& S^{2}=\frac{n \sum \mathrm{f}_{\mathrm{i}} \mathrm{x}_{\mathrm{i}}{ }^{2}-\left(\sum \mathrm{f}_{\mathrm{i}} \mathrm{x}_{\mathrm{i}}\right)^{2}}{n(\mathrm{n}-1)} \\
& S^{2}=\frac{36.238833(2902)^{2}}{36(36-1)} \\
& S^{2}=\frac{8597988-8421604}{36(35)} \\
& S^{2}=\frac{176384}{1260} \\
& S^{2}=139,98 \\
& S=\sqrt{139,98} \\
& S=11,83
\end{aligned}
$$

Jadi nilai simpangan baku kelas eksperimen adalah 11,83.

Untuk mencari nilai kooefisien kemiringan kurva dengan menggunakan rumus Karl Person maka dimasukkan data dari nilai rata-rata, modus dan simpangan baku yang telah didapat untuk melihat apakah normal atau tidak data tersebut sebagai berikut:

Kooefisien Kemiringan Kurva:

SKP $=\frac{\bar{x}-\mathrm{M}_{0}}{\mathrm{~S}} \quad$ (Fajri, 2018:119)

$S K P=\frac{81-78,2}{11,83}$

$S K P=\frac{2,8}{11,83}$

$S K P=0,23$

Data terdistribusi normal karena SKP: 0,23 antara (-1) dan $(+1)$, maka data kelas eksperimen terdistribusi normal.

\section{Uji Normalitas Data Kelas Kontrol}

Yang menjadi kelas kontrol adalah kelas $X$ TKRO 1 yang tidak menggunakan perlakuan dalam proses pembelajaran, siswa kelas $X$ TKRO 1 berjumlah 36 siswa, berikut merupakan nilai tes hasil belajar siswa kelas X TKRO 1 .

$\begin{array}{llllll}60 & 70 & 70 & 45 & 55 & 75 \\ 60 & 55 & 60 & 60 & 65 & 70 \\ 60 & 60 & 50 & 45 & 65 & 70 \\ 60 & 75 & 70 & 80 & 60 & 80 \\ 65 & 60 & 60 & 80 & 80 & 55 \\ 70 & 55 & 65 & 65 & 70 & 60\end{array}$

Data nilai tes hasil belajar siswa kelas $X$ TKRO 1 sebagai kelas kontrol yang tidak diberi perlakuan dalam proses pembelajaran hanya menggunakan metode ceramah menunjukkan hanya ada 7 siswa yang memenuhi KKM, sedangkan siswa lainnya mendapatkan nilai di bawah nilai KKM. Nilai terendah yang didapatkan siswa adalah 45 sedangkan nilai tertinggi yang didapatkan siswa yaitu 80 . Kemudian disusun dalam daftar distribusi frekuensi dengan langkah-langkah menentukan rentang, banyak kelas, dan panjang kelas sebagai berikut:

1. Rentang

$R=X_{\max }-X_{\min }$ (Sumardi, 2020:160)

$R=80-45$

$R=35$

2. Banyak Kelas Interval

$$
\begin{aligned}
& K=1+(3,3) \log n \\
& K=1+(3,3) \log 36 \\
& K=1+(3,3) 1,55 \\
& K=1+5,13 \\
& K=6,13 \\
& K=6
\end{aligned}
$$

\begin{tabular}{|c|c|c|c|c|c|c|}
\hline No. & $\begin{array}{c}\text { Kelas } \\
\text { Interval }\end{array}$ & $\mathrm{Fi}$ & $\mathbf{X i}$ & Fi.Xi & $\mathrm{X}^{2}$ & Fi.Xi' \\
\hline 1. & $45-50$ & 3 & 47,5 & 142,5 & 2256,25 & 6768,75 \\
\hline 2. & $51-56$ & 4 & 53,5 & 214 & 2862,25 & 11449 \\
\hline 3. & $57-62$ & 11 & 59,5 & 654,5 & 3540,25 & 38942,75 \\
\hline 4. & $63-68$ & 6 & 66,5 & 399 & 4290,25 & 25741,5 \\
\hline 5. & $69-74$ & 7 & 71,5 & 500,5 & 5112,25 & 35785,75 \\
\hline 6. & $75-80$ & 5 & 77,5 & 387,5 & 6006,25 & 30031,75 \\
\hline & Jumlah & $\begin{array}{l}\mathrm{Fi} \\
= \\
36\end{array}$ & $\begin{array}{l}X i= \\
375\end{array}$ & $\begin{array}{c}\sum F i . X i \\
=2298\end{array}$ & $\begin{array}{l}\sum X i^{2}= \\
24067,5\end{array}$ & $\begin{array}{r}\sum F i . X i^{2} \\
=148718,5\end{array}$ \\
\hline
\end{tabular}

Jadi, banyak kelas yang di ambil adalah 6 .

3. Panjang Kelas Interval

$$
\begin{aligned}
& I=\frac{r}{k} \\
& I=\frac{35}{6} \\
& I=6 \\
& \text { Jadi panjang kelas interval adalah } 6 .
\end{aligned}
$$

Setelah didapat nilai di atas, maka akan dimasukkan ke dalam tabel distribusi frekuensi. Untuk lebih jelasnya tabel daftar distribusi kelas eksperimen seperti di bawah ini:

Tabel 2

Daftar Distribusi Frekuensi Kelas Kontrol

Terlihat pada tabel daftar distribusi kelas kontrol yaitu kelas X TKRO 1 menunjukkan yang paling banyak mendapatkan nilai yaitu pada nilai 
57-62 dengan jumlah 11 orang, dan yang paling sedikit yaitu mendapatkan nilai $45-50$ hanya 3 orang. Data dalam diagram dapat dilihat pada gambar di bawah:

\section{Gambar 2}

\section{Diagram Distribusi Frekuensi Hasil Belajar}

Kelas Kontrol

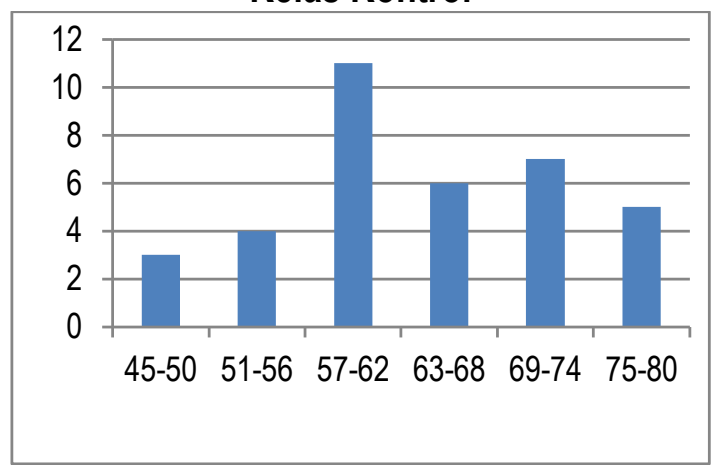

Selanjutnya mencari nilai rata-rata, modus, dan simpangan baku dari hasil belajar kelas kontrol. Yang akan dilihat pada data di bawah ini:

4. Nilai Rata-rata kelas kontrol

$$
\begin{aligned}
& \bar{x}=\frac{\sum \mathrm{Fi} . \mathrm{Xi}}{\sum \mathrm{Fi}} \\
& \bar{x}=\frac{2298}{36} \\
& \bar{x}=63,8
\end{aligned}
$$

Jadi, nilai rata-rata pada kelas kontrol adalah 63,8 .

5. Modus

$$
\begin{aligned}
& b=57-0,5=56,5 \\
& b_{1}=11-4=7 \\
& b_{2}=11-6=5 \\
& p=6 \\
& \text { Mo }=b+p\left(\frac{b_{1}}{b_{1}+b_{2}}\right) \\
& \text { Mo }=56,5+6\left(\frac{7}{7+5}\right) \\
& \text { Mo }=56,5+3,48 \\
& \text { Mo }=59,98 \\
& \text { Mo }=6
\end{aligned}
$$

Jadi nilai modus pada kelas kontrol adalah 6.
6. Simpangan Baku

$$
\begin{aligned}
& S^{2}=\frac{n \sum \mathrm{f}_{\mathrm{i}} \mathrm{x}_{\mathrm{i}}{ }^{2}-\left(\sum \mathrm{f}_{\mathrm{i}} \mathrm{x}_{\mathrm{i}}\right)^{2}}{n(n-1)} \\
& \mathrm{S}^{2}=\frac{36.148718,5(2298)^{2}}{36(36-1)} \\
& \mathrm{S}^{2}=\frac{5353866-5280804}{36(35)} \\
& \mathrm{S}^{2}=\frac{73062}{1260} \\
& \mathrm{~S}^{2}=57,98 \\
& \mathrm{~S}=\sqrt{57,98} \\
& \mathrm{~S}=7,61 \\
& \text { Jadi nilai simpangan baku kelas kontrol } \\
& \text { adalah 7,61. }
\end{aligned}
$$

Selanjutnya akan di uji kooefisien kemiringan kurva dengan rumus Karl Person untuk mengetahui apakah normal atau tidak data yang telah di cari di atas.

Kooefisien Kemiringan Kurva:

$$
\begin{aligned}
& S K P=\frac{\bar{x}-\mathrm{M}_{0}}{\mathrm{~S}} \\
& S K P=\frac{6,38-60}{7,61} \\
& S K P=\frac{3,8}{7,61}
\end{aligned}
$$$$
S K P=0,49
$$

Data terdistribusi normal karena SKP: 0,49 , dan data kelas kontrol dapat dikatakan normal.

\section{Uji Homogenitas Data}

Uji homogenitas merupakan uji untuk memberikan informasi bahwa data penelitian masing-masing kelompok berasal dari populasi yang tidak berbeda jauh keragamannya (Fajri, 2018:201). Pada penelitian ini uji homogenias data menggunakan Barlett, uji ini digunakan untuk menguji sampel yang berasal dari dua kelompok atau lebih (Fajri, 2018:208).

Untuk menentukan harga $\mathrm{S}^{2}$ gab dengan menentukan tabel bantu berikut ini:

Tabel 3

Uji Homogenitas Kelas Eksperimen dan Kelas Kontrol

\begin{tabular}{|c|c|c|c|c|}
\hline Kelas & $\mathbf{D k}$ & $\mathbf{S}_{\mathbf{1}}{ }^{2}$ & $\log \mathbf{S}_{\mathbf{1}}{ }^{2}$ & $\mathbf{( d k )} \log \mathbf{S}{ }^{2}$ \\
\hline Eksperimen & 35 & 140 & 2,146 & 75,11 \\
\hline Kontrol & 35 & 57,98 & 1,763 & 61,705 \\
\hline Jumlah & $\mathbf{7 0}$ & - & - & $\mathbf{1 3 6 , 8 1 5}$ \\
\hline
\end{tabular}


Varians Semua Gabungan:

$$
\begin{aligned}
& S_{\text {gab }}=\frac{\left(n_{\mathrm{e}}-1\right) S_{\mathrm{e}}^{2}+\left(n_{k}-1\right) S_{k}^{2}}{\left(n_{\mathrm{e}}+n_{k}-2\right)} \quad \text { Fajii, 2018:209) } \\
& S^{2}{ }_{\text {gab }}=\frac{(36-1) 140+(36-1) 57,98}{(36+36-2)} \\
& S^{2}{ }_{\text {gab }}=\frac{4900+2029,3}{70} \\
& S^{2}{ }_{\text {gab }}=\frac{6929,3}{70} \\
& S^{2}{ }_{\text {gab }}=98,99 \\
& S_{\text {gab }}=\sqrt{ } 98,99 \\
& S_{\text {gab }}=9,949
\end{aligned}
$$

Kemudian di cari harga satuan $B$ dengan rumus:

$B=\left(\log S^{2}{ }_{\text {gab }}\right) \sum(n-1)$

$B=\log 98,99 \times 70$

$B=139,69$

Dari perhitungan di atas diperoleh nilai $x^{2}$ yakni: $x^{2}=(\ln 10)\left(B-\sum \mathrm{dk}\left(\operatorname{logs}^{2}\right)\right)$

$x^{2}=(2,3026)(139,69-138,315)$

$x^{2}=(2,3025)(1,375)$

$x^{2}=3,166$

Ditentukan harga $x^{2}$ tabelyaitu $\mathrm{dk}=\mathrm{k}-1=2$ $1=1$ sehingga $x^{2}$ tabel $=3,841$ sedangkan harga $x^{2}$ hitung $=3,166$. Jadi $x^{2}$ hitung $<x^{2}$ tabel atau $3,166<$ 3,841 maka dapat disimpulkan bahwa data memiliki varians yang homogen artinya kelas sampel berasal dari populasi yang sama. Kelas eksperimen dan kelas kontrol memiliki data normal dan homogen. Kemudian selanjutnya dilakukan uji hipotesis menggunakan uji-t.

\section{Uji Hipotesis Data}

Setelah dilakukan uji normalitas dan uji homogenitas maka dilanjutkan dengan uji hipotesis. Pengujian hipotesis adalah pengujian terhadap suatu pernyataan dengan menggunakan metode statistik sehingga hasil pengujian tersebut dapat dinyatakan signifikan secara statistik. Pengujian hipotesis merupakan bagian dari statistik infernsial. Hipotesis merupakan pernyataan yang kebenarannya masih lemah. Agar pernyataannya tidak diragukan maka secara statistik kita bisa melakukan pengumpulan data dan melakukan pengujian. Dengan melakukan pengujian statistik terhadap hipotesis kita dapat memutuskan apakah hipotesis dapat diterima (data tidak memberikan bukti untuk menolak) atau ditolak (data memberikan bukti untuk menolak hipotesis). Pengujian Hipotesis ini adalah $\mathrm{H}_{0}$ di terima jika $-\mathrm{t}_{\alpha / 2} \leq \mathrm{t}_{0} \leq \mathrm{t}_{\mathrm{a} / 2}$. Dalam $\mathrm{Hal}$ ini $\mathrm{H}_{\circ}$ dengan huruf signifikan $5 \%$ dimana $d k=n_{1}+n_{2}-2$ dan peluang $(1-1 / 2 \alpha)$. Pengujian hipotesis menggunakan statistik parametris Uji-t.

Dari data sebelumnya didapat sebagai berikut:

$$
\begin{array}{lll}
\mathrm{S}_{1}{ }^{2}=140 & \mathrm{n}_{1}=36 \quad \mathrm{X}_{1}=81 \\
\mathrm{~S}_{2}{ }^{2}=57,98 & \mathrm{n}_{2}=36 \quad \mathrm{X}_{2}=68,3
\end{array}
$$

Sebelum menghitung Uji-t, harus dilakukan dulu perhitungan $\mathrm{S}^{2}$ gab yang telah didapat sehingga:

$$
\begin{aligned}
& S_{\text {gab }}^{2}=\frac{\left(n_{\mathrm{e}}-1\right) S_{\mathrm{e}}^{2}+\left(n_{\mathrm{k}}-1\right) S_{\mathrm{k}}^{2}}{\left(\mathrm{n}_{\mathrm{e}}+n_{\mathrm{k}}-2\right)} \\
& \mathrm{S}_{\text {gab }}=\frac{(36-1) 140+(36-1) 57,98}{(36+36-2)} \\
& S_{\text {gab }}=\frac{4900+2029,3}{70} \\
& S_{\text {gab }}^{2}=\frac{6929,3}{70} \\
& S_{\text {gab }}^{2}=98,99 \\
& S_{\text {gab }}=\sqrt{ } 98,99 \\
& S_{\text {gab }}=9,949
\end{aligned}
$$

Maka menghitung Uji-t dengan rumus:

$$
\begin{aligned}
& t=\frac{\bar{x}-\bar{x}}{\sqrt[2]{\frac{1}{n_{1}+\frac{1}{n_{2}}}}} \\
& t=\frac{81-63.8}{\sqrt[9,949]{\frac{1}{36}+\frac{1}{36}}} \\
& t=\frac{17,2}{9,949} \\
& t=\frac{17,2}{0,054} \\
& t=\frac{17,2}{2,28} \\
& t=7,54
\end{aligned}
$$

Berdasarkan perhitungan di atas maka diperoleh $t_{\text {hitung }}$ adalah 7,54 , dan tabel $_{\text {dengan }} \mathrm{dk}$ $=\mathrm{n}_{1}+\mathrm{n}_{2}-2$ dan taraf signifikan $5 \%$ maka tabel adalah 1,67. Sehingga thitung $>t_{\text {tabel }}$ maka $\mathrm{H}_{0}$ ditolak sesuai dengan criteria pengujian hipotesis yaitu tolak $\mathrm{H}_{0}$ jika hitung $>t_{\text {tabel }}$ di mana $d k=n_{1}+n_{2}-2$ dan peluang $(1-a)$. Sehingga dapat disimpulkan bahwa ada pengaruh positif yang signifikan dari media pembelajaran Youtube di mana kelas eksperimen lebih baik di pada kelas kontrol. Sesuai dengan rumusan hipotesis $\mathrm{H}_{a}$ 
diterima dan $\mathrm{H}_{\mathrm{o}}$ ditolak bahwa "Terdapat pengaruh penggunaan media pembelajaran Youtube terhadap hasil belajar siswa pada mata pelajaran sejarah di SMK PGRI 2 Palembang".

\section{Pembahasan}

Berdasarkan hasil penelitian yang telah dilakukan di SMK PGRI 2 Palembang dengan mengambil 2 sampel yakni kelas $X$ TKRO 2 sebagai kelas eksperimen yang diberi perlakuan menggunakan media Youtube sebagai media pembelajaran dan sebagai kelas kontrol yakni kelas $\mathrm{X}$ TKRO 1 hanya dilakukan metode ceramah dalam proses pembelajaran, yang dijadikan sampel sebanyak 72 siswa. Setelah melakukan proses pembelajaran maka dilakukan tes hasil belajar pada siswa dengan materi yang sama yakni, 20 soal pilihan ganda. Pada hasil tes hasil belajar siswa maka diperoleh nilai pada kelas eksperimen nilai rataratanya adalah 81 di atas nilai KKM. Sedangkan pada kelas kontrol siswa yang tuntas hanya nilai rata-ratanya adalah 63,8 itu menunjukkan nilai di bawah nilai KKM.

Setelah dilakukan penelitian kemudian dilakukan analisis data dan diperoleh data pada uji normalitas data nilai pada kelas eksperimen adalah 0,23 , hal tersebut termasuk kategori normal karena di antara (-1) dan $(+1)$, sedangkan kelas kontrol mendapatkan nilai 0,49 sehingga dikatakan terdistribusi normal. Kemudian pada uji homogenitas data diperoleh $x^{2}$ tabel $=3,841$ sedangkan harga $x^{2}$ hitung $=3,166$. Jadi $x^{2}$ hitung $<x^{2}$ tabel atau 3,166 $<3,841$ maka dapat disimpulkan bahwa data memiliki varians yang homogen artinya kelas sampel berasal dari populasi yang sama. Kelas eksperimen dan kelas kontrol memiliki data normal dan homogen. Selanjutnya pada uji hipotesis hasil dari analisis t-tes maka diperoleh thitung adalah 7,54 , dan tabel dengan $\mathrm{dk}=\mathrm{n}_{1}+\mathrm{n}_{2}-2$ dan taraf signifikan $5 \%$ maka tabel adalah 1,67 . Sehingga $t_{\text {hitung }}>$ tabel maka $\mathrm{H}_{0}$ ditolak dan $\mathrm{H}_{\mathrm{a}}$ diterima sesuai dengan kriteria pengujian hipotesis yaitu tolak $\mathrm{H}_{0}$ jika thitung $>$ tabel dimana $\mathrm{dk}=\mathrm{n}_{1}+\mathrm{n}_{2}-2$ dan peluang (1-a). Sehingga dapat disimpulkan bahwa ada pengaruh positif yang signifikan terhadap hasil belajar siswa.

Hasil penelitian tersebut senada dengan penelitian Anisa Isnaini Uwadiah "Pengaruh
Penggunaan Media Sosial Youtube Terhadap Kreatifitas Siswa pada mata pelajaran Seni Budaya dan Prakarya (SBdP) di SDN 1 Nologaten Ponorogo Tahun Pelajaran 2018/2019" (Huwaidah, 2018:5). Hal ini diketahui dari hasil perhitungan dengan menggunakan statistika yaitu Fhitung sebesar 6,01 dan Ftabel pada taraf signifikasi 5\% sebesar 4,22. Maka Ha diterima yang artinya ada pengaruh signifikan Media Sosial Youtube Terhadap Kreativitas Siswa Kelas V di SDN Nologaten 1 Ponorogo. Karena Fhitung>Ftabel, maka $\mathrm{H}_{0}$ ditolak (Huwaidah, 2018:5). Kemudian penelitian yang dilakukan Munasiatul Ifadah dengan judul "Pengaruh Penggunaan Media Sosial Youtube terhadap Perilaku Positif Siswa Kelas 5 di MI Nurul Iman Kebonsari Madiun Tahun Ajaran 2019/2020 (Ifadah, 2020:1). Berdasarkan analisis data ditemukan bahwa terdapat pengaruh yang signifikan antara media sosial Youtube terhadap perilaku positif siswa kelas 5 di MI Nurul Iman Kebonsari Madiun tahun ajaran 2019/2020. Hal ini diketahui dari hasil perhitungan menggunakan SPSS yaitu Fhitung $(4,686)>$ Ftabel $(2,04)$ sehingga $\mathrm{H}_{0}$ ditolak hal ini diperoleh dari hasil angket siswa dengan rincian $56,25 \%$ dengan frekuensi 18 dari 32 responden.

Dengan demikian sesuai dengan rumusan hipotesis $\mathrm{H}_{a}$ diterima dan $\mathrm{H}_{0}$ ditolak dapat disimpulkan bahwa "Terdapat pengaruh penggunaan media pembelajaran Youtube terhadap hasil belajar siswa pada mata pelajaran sejarah di SMK PGRI 2 Palembang".

\section{SIMPULAN}

Berdasarkan hasil penelitian yang telah dilakukan di SMK PGRI 2 Palembang dan hasil analisis data, maka dapat disimpulkan sebagai berikut:

1. Kegiatan pembelajaran pada kelas eksperimen dengan menggunakan media Youtube sebagai media pembelajaran, terbukti lebih baik dari pada kelas kontrol yang tidak diberi perlakuan dalam kegiatan pembelajaran, ini dibuktikan pada nilai tes hasil belajar siswa yang menunjukkan pada kelas eksperimen lebih banyak yang memenuhi KKM, sebaliknya pada kelas kontrol siswa banyak yang tidak memenuhi 
KKM. Kemudian dari nilai rata-rata siswa kelas eksperimen yakni kelas X TKRO 2 mendapatkan nilai 81, sedangkan pada kelas kontrol yakni kelas X TKRO 1 siswa mendapatkan nilai 63,8 . Ini menunjukkan bahwa kelas eksperimen yang diberikan perlakuan menggunakan media Youtube pada proses pembelajaran lebih unggul dari pada kelas kontrol yang hanya menggunakan metode ceramah dalam proses pembelajaran dan pemanfaatan media Youtube dalam proses pembelajaran dapat memberikan pengaruh yang positif terhadap hasil belajar siswa.

2. Hasil perhitungan yang terdapat pada Uji-t yaitu diperoleh thitung adalah 7,54, dan tabel dengan $\mathrm{dk}=\mathrm{n}_{1}+\mathrm{n}_{2}-2$ dan taraf signifikan $5 \%$ maka tabel adalah 1,67 . Sehingga $t_{\text {hitung }}$ $>$ tabel maka $\mathrm{H}_{0}$ ditolak dan $\mathrm{H}_{\mathrm{a}}$ diterima sesuai dengan kriteria pengujian hipotesis yaitu tolak $\mathrm{H}_{\mathrm{o}}$ jika thitung $>$ tabe/ dimana $\mathrm{dk}=$ $n_{1}+n_{2}-2$ dan peluang (1-a). Sehingga dapat disimpulkan bahwa ada pengaruh positif yang signifikan dari media pembelajaran Youtube di mana kelas eksperimen lebih baik dari pada kelas kontrol.

\section{DAFTAR PUSTAKA}

Agung, Leo dan Sri Wahyuni. 2013. Perencanaan Pembelajaran Sejarah. Yogyakarta: Penerbit Ombak.

Duli, Nikolaus. 2019. Metodologi Penelitian Kuantitatif: Beberapa Konsep Dasar Untuk Penulisan Skripsi \& Analsis Data dengan SPSS. Yogyakarta: Deepublisher.

Fajri, Ismail. 2018. Statistika Untuk Penelitian Pendidikan dan IImu-ilmu Sosial. Jakarta: Prenadamedia Group.

Hakim, Thursan. 2008. Belajar Secara Efektif. Jakarta: Puspa Swara.

Hanafi, dkk. 2018. Profesionalisme Guru dalam Pengelolaan Kegiatan Pembelajaran di Sekolah. Yogyakarta: Deepublish.
Huwaidah, Anisa Isnaini. 2019. "Pengaruh Penggunaan Media Sosial Youtube Terhadap Kreativitas Siswa pada Mata Pelajaran Seni Budaya dan Prakarya di SDN 1 Nologaten Ponorogo Tahun Ajaran 2018/2019". Dalam Skripsi. Jurusan Pendidikan Guru Madrasah Ibtidaiyah. Fakultas Terbiyah dan ilmu keguruan. Institut Agma Islam Negeri Ponogoro.

Ifadah, Munasiatul. 2020. "Pengaruh Penggunaan Media Sosial Youtube Terhadap Perilaku Positif Siswa Kelas 5 di MI Nurul Iman Kebonsari Madiun Tahun Ajaran 2019/2020". Dalam Skripsi. Jurusan Pendidikan Guru Madrasah Ibtidaiyah. Fakultas Terbiyah dan ilmu keguruan. Institut Agma Islam Negeri Ponogoro.

Rifai, Rochmannudin. 2020. "Pengaruh Media Sosial Youtube Terhadap Minat dan Hasil Belajar Siswa Mata Pelajaran PAI di SMAN 1 Gondang Tulungagung". Dalam Skripsi. Pendidikan Agama Islam. Fakultas Tarbiyah dan Ilmu Keguruan. IAIN Tulung Agung.

Sumardi. 2020. Teknik Pengukuran dan Penilaian Hasil Belajar. Yogyakarta: Deepublish. 


\section{KETENTUAN PENULISAN ARTIKEL JURNAL KALPATARU}

1. Naskah berbahasa Indonesia yang disempurnakan bertemakan kesejarah yang meliputi hasil penelitian sejarah, pengajaran sejarah dan penelitian kebudayaan.

2. Naskah harus asli dan belum pernah dimuat dalam media lain. Naskah dapat berupa hasil penelitian/artikel kajian konseptual yang ditulis oleh perorangan dan atau kelompok.

3. Naskah ditulis dengan cara-cara yang sesuai dengan ketentuan penulisan artikel ilmiah menggunakan bahasa Indonesia yang baku, berupa ketikan, beserta soft file dalam CD-RW atau dengan mengirimkan email pada redaksi jurnal Kalpataru dengan alamat jurnalkalpatarusejarah@gmail.com, spasi tunggal, jenis huruf arial narrow ukuran 12, dengan panjang naskah antara 8-15 halaman pada kertas A4.

4. Artikel hasil penelitian memuat:

JUDUL

Nama Penulis

Abstrak

A. PENDAHULUAN

B. METODE PENELITIAN

C. HASIL DAN PEMBAHASAN

D. SIMPULAN

DAFTAR PUSTAKA
: XXX (HURUF KAPITAL)

: (disertai jabatan, institusi, dan email)

: (Bahasa Indonesia yang memuat 100-200 kata diikuti kata kunci, dengan jenis huruf arrial narrow dan ukuran huruf 11 serta dicetak miring).

: (memuat latar belakang masalah, tinjauan pustaka secara ringkas, masalah penelitian, dan tujuan penelitian).
: (berisi simpulan).

: (berisi pustaka yang dirujuk dalam uraian naskah).

5. Artikel Kajian Konseptual memuat:

\section{JUDUL \\ Nama Penulis \\ Abstrak \\ PENDAHULUAN \\ Sub Judul
Simpulan
DAFTAR PUSTAKA}

\section{: XXX (HURUF KAPITAL)}

: (disertai jabatan, institusi, dan email)

: (Bahasa Indonesia yang memuat 100-200 kata diikuti kata kunci, dengan jenis huruf arrial narrow dan ukuran huruf 11 serta dicetak miring.

: (memuat latar belakang masalah, tinjauan pustaka secara ringkas, masalah penelitian, dan tujuan penelitian).

: Sesuai dengan kebutuhan (tanpa numbering).

: (berisi simpulan dan saran).

6. Referensi sumber dalam teks artikel ditulis dengan menggunakan side note, contoh (Jalaludin, 1991:79); sementara penulisan daftar pustaka disusun dengan ketentuan. Nama pengarang. Tahun terbit. Judul (dicetak miring). Kota terbit: Nama Penerbit. Contoh: Koentjaraningrat. 2010. Manusia dan Kebudayaan di Indonesia. Jakarta: Djambatan. Daftar pustaka hanya memuat pustaka/sumber yang dirujuk dalam uraian dan disusun menurut abjad tanpa nomor urut.

7. Naskah yang dimuat akan disunting kembali oleh redaksi tanpa mengubah isinya.

8. Naskah yang ditolak (tidak bisa dimuat) akan dikirim kembali ke penulis dengan pemberitahuan tertulis dari redaksi atau melalui email.

9. Penulis yang naskahnya dimuat akan mendapat 1 (satu) majalah nomor yang bersangkutan.

10. Kontak person: Muhamad Idris (081271498618); Eva Dina Chairunisa (082281267851); Jeki Sepriady (085269261780). 